Eur. J. Clin. Chem. Clin. Biochem.

Vol. 31, 1993, pp. 69-74

(C) 1993 Walter de Gruyter \& Co.

Berlin - New York

\title{
Correlation of Atrial Natriuretic Peptide and Cyclic Guanosine Monophosphate Plasma Concentrations in Patients with Heart Disorders During Rest and Exercise
}

\author{
By T. Szekeres ${ }^{1}$, Erika Artner-Dworzak ${ }^{2}$, B. Puschendorf ${ }^{2}$, Monika Fritzer $^{1}$, M. Havel ${ }^{3}$, A. Gassner ${ }^{4}$ and \\ L. Fridrich ${ }^{5}$ \\ 1 Institut für Medizinische Chemie der Universität Wien, Wien, Austria \\ ${ }^{2}$ Institut für Medizinische Chemie und Biochemie der Universität Innsbruck, Innsbruck, Austria \\ ${ }^{3}$ II. Chirurgische Universitätsklinik, Universität Wien, Wien, Austria \\ ${ }^{4}$ Rehabilitationszentrum Hochegg, Grimmenstein, Austria \\ ${ }^{s}$ Klinik für Nuklearmedizin, Universität Innsbruck, Innsbruck, Austria
}

(Received July 13/October 16, 1992)

Summary: The concentration of atrial natriuretic peptide was measured in order to evaluate its importance in patients suffering from a variety of cardiac diseases. There was a correlation between plasma concentrations of atrial natriuretic peptide and its "second messenger" cyclic guanosine monophosphate (cGMP) in all of the cases examined. We investigated the relationship between atrial natriuretic peptide and cGMP plasma concentrations during rest and exercise in comparison with the scintigraphically assessed left- and rightventricular ejection fraction in patients with chronic heart disease $(n=20)$, and after orthotopic heart transplantation $(n=16)$; plasma concentrations were also measured in healthy controls $(n=14)$. Atrial natriuretic peptide and cGMP concentrations showed a similar correlation during rest and exercise with $\mathrm{r}=0.74$ and $\mathrm{r}=0.81$, respectively. With the exception of patients after heart transplantation, a significant negative correlation was seen between the left ventricular ejection fraction and atrial natriuretic peptide or cGMP plasma concentrations during rest conditions ( $r=0.76$ or 0.58 , respectively). No correlation was apparent between plasma concentrations of atrial natriuretic peptide or cGMP and the left- or right ventricular ejection fraction during exercise.

The concentrations of atrial natriuretic peptide and cGMP in plasma differed significantly between healthy controls and patients during rest and exercise. It is noteworthy that atrial natriuretic peptide and cGMP concentrations were markedly higher in patients after heart transplantation than in patients suffering from chronic heart disease. Our results indicate that plasma atrial natriuretic peptide and cGMP concentrations. are sensitive markers of cardiac impairment.

\section{Introduction}

Atrial natriuretic peptide is released by heart muscle cells of both atrias and ventricles in response to increased intracardial pressure, tachyarrhythmia, cardiay congestion and renal failure $(1-4)$. It causes diuresis, natriuresis and vasodilatation to decrease blood volume (5). Cyclic guanosine monophosphate (cGMP) is known to act as the "second messenger" of atrial natriuretic peptide $(6,7)$. It has been shown that plasma atrial natriuretic peptide and cGMP concentrations correlate reasonably well under resting conditions $(9-13)$, and this is confirmed by our recent findings (8).

Only a few reports have been published concerning the relationship between haemodynamic variables and the atrial natriuretic peptide-cGMP system. Moreover, these reports do not allow an assessment of 
whether plasma atrial natriuretic peptide or cGMP concentrations of whether plasma atrial natriuretic peptide or cGMP concentrations are clinically useful in the evaluation of patients with heart diseases.

We have already reported the normal range of atrial natriuretic peptide and cGMP in healthy volunteers (9) and atrial natriuretic peptide concentrations in patients suffering from various heart diseases in correlation with scintigraphically assessed ventricular function under resting conditions (14). Recently, Vorderwinkler et al. suggested that cGMP might be better suited as a marker for cardiac insufficiency than atrial natriuretic peptide; this was based on a comparison of biochemical markers with rough clinical signs of cardiac insufficiency (8).

The aim of the present study was to examine plasma concentrations of atrial natriuretic peptide and cGMP in order to evaluate their relative importance as screening quantities in the diagnosis of heart diseases. We compared atrial natriuretic peptide and cGMP plasma values with scintigraphically assessed left and right ventricular ejection fractions and determined plasma atrial natriuretic peptide and cGMP in different patient groups, including patients after orthotopic heart transplantation during rest and exercise. Our data show that

(a) plasma atrial natriuretic peptide and cGMP are increased in all patients,

(b) atrial natriuretic peptide and cGMP concentrations correlate well particularly under exercise conditions, and

(c) their increases can be used as a marker for pathological alterations during cardiovascular disorders.

\section{Materials and Methods}

\section{Plasma samples}

For determination of atrial natriuretic peptide, a $4 \mathrm{ml}$ blood specimen was drawn into pre-chilled tubes coated with dipotassium EDTA; $0.1 \mathrm{ml}$ (200 kallikrein inhibitory units) aprotinin solution was added, and the samples were chilled in ice water. The samples were centrifuged for 30 minutes at $4^{\circ} \mathrm{C}$ at $1700 \mathrm{~g}$. Plasma samples for the determination of cGMP concentrations were treated in the same way as for atrial natriuretic peptide but without adding aprotinin. After centrifugation, plasma was divided into aliquots and frozen at $-20^{\circ} \mathrm{C}$ until used for the assay. The samples were drawn during baseline and exercise conditions as defined later.

Direct radioimmunoassay of atrial natriuretic pep. tide

For the measurement of atrial natriuretic peptide, a commercially available ${ }^{125}$ I radioimmunoassay kit (Eiken Chemical Company Ltd., Tokyo, Japan, purchased from Behring Insti- tute, Vienna, Austria) was used. The interassay CV was $16 \%$ and the method correlated well with an established atrial natriuretic peptide radioimmunoassay using pre-analytical extraction of the plasma samples as described previously (14).

\section{Radioimmunoassay of cGMP}

For cGMP determination we employed the ${ }^{125} I$ radioimmunoassay kit obtained from Amersham International Ltd., Amersham, Bucks, U.K. after extraction of samples with ether. As reported earlier, the interassay $C V$ was $12.2 \%$ (8).

The assays of atrial natriuretic peptide and cGMP plasma concentrations were performed independently in two different laboratories without knowing the donor's health status or ventricular function.

\section{Patients and controls}

A total of 50 individuals, comprising 14 healthy controls, 20 patients with defined heart disease (coronary heart disease 16; cardiomyopathy 4) as well as 16 patient after orthotopic heart transplantation were included in this study. All patients were examined only after their dismissal from the acute care facility and while they were in a stable chronic stage of their disease during rehabilitation. Beta-blocking drugs were withdrawn three days, and all other cardiac-active and vasodilating drugs one day before blood sampling and exercise radionuclide ventriculography.

Exercise radionuclide ventriculography and blood sampling

The patients and controls were supine 20 minutes before starting exercise radionuclide ventriculography. The first plasma sample was taken at the end of the scintigraphic imaging period while the subject was resting. To evaluate plasma concentrations of atrial natriuretic peptide and CGMP in relation to scintigraphically assessed left ventricular ejection fraction and right ventricular ejection fraction during stress, step-wise supine bicycle load exercise was performed $(25-125$ Watt); at the end of the peak exercise period ( 5 minutes) repeated blood samples were drawn. All patients were monitored for heart rate and blood pressure during sampling. The scintigraphic technique was used for the simultaneous determination of the left and right ventricular ejection fraction as described elsewhere (15). Significant valvular regurgitation was scintigraphically excluded by assessment of the regurgitant index (16).

Healthy volunteers in an exercise training programme were used as normal controls. Since the examination of healthy individuals by scintigraphy is not permitted in Austria, their normal echocardiographic heart function was assumed to represent a normal left ventricular ejection fraction range (range $65 \pm 7.5 \%$ ). As expected these individuals were excluded from exercise scintigraphy.

Eight plasma samples drawn under exercise were excluded from the atrial natriuretic peptide or CGMP analysis because of haemolysis or clotting.

\section{Statistical analysis}

Mean values, standard deviations, linear regressions, correlations and significancies were determined with the aid of the "SPSS" statistical program package. Ventricular function and concentrations of atrial natriuretic peptide or cGMP were analysed by both parametric and non ${ }_{7}$ parametric tests. The Student-Newman-Keuls test, T-test, Kruskal-Wallis-ANOVA, as well as the Mann-Whitney U-test were used to analyse group differences. Changes from rest to exercise were analysed by the paired T-test and Wilcoxon-test. 


\section{Results}

Comparison of atrial natriuretic peptide and cGMP plasma concentrations

Concentrations of atrial natriuretic peptide and cGMP in the plasmas of 36 individuals were compared during rest and exercise (fig. 1): 20 with defined heart disease and 16 after orthotopic heart transplantation during rest (fig. 1a) and exercise (fig. 1b). There was a significant direct correlation between the concentrations of atrial natriuretic peptide and cGMP $(\mathrm{r}=0.74 ; \mathrm{y}=0.03 \mathrm{x}+2.6 ; \mathrm{p}<0.001)$ during rest as well as during exercise $(r=0.81 ; y=0.03 x+4.3$; $\mathrm{p}<0.001$ ) (fig. 1b).
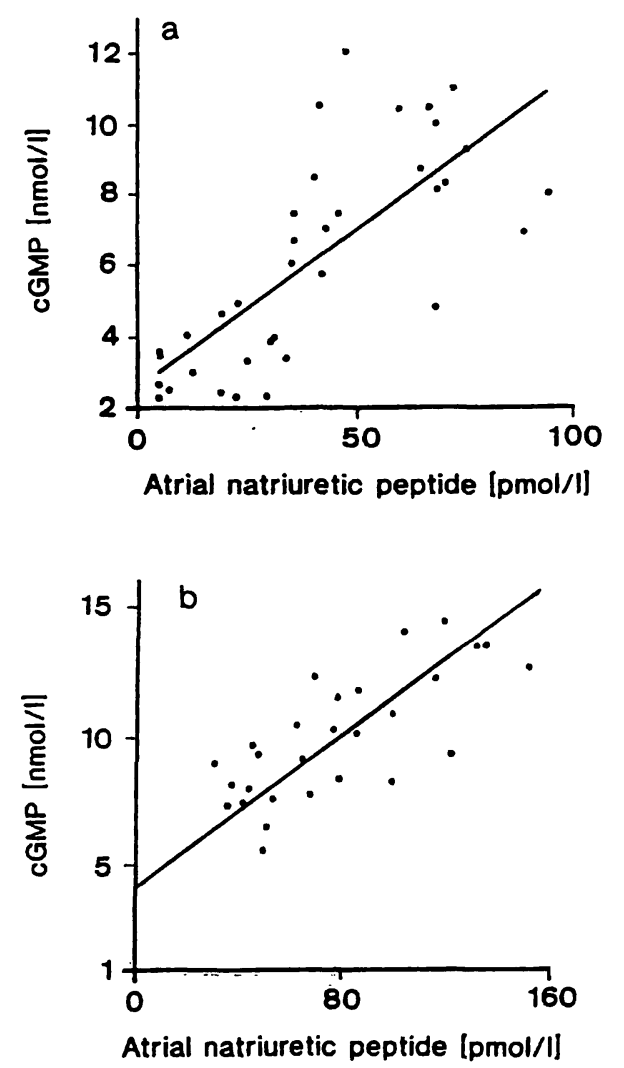

Fig. 1. Comparison of atrial natriuretic peptide and cGMP plasma concentrations during rest (a) and exercise (b).

(a) correlation between atrial natriuretic peptide and cGMP during rest: $\mathrm{n}=36 ; \mathrm{r}=0.74 ; \mathrm{y}=0.03 \mathrm{x}+2.6 ; \mathrm{p}<0.001$.

(b) correlation between atrial natriuretic peptide and cGMP during exercise:

$\mathrm{n}=28 ; \mathrm{r}=0.81 ; \mathrm{y}=0.03 \mathrm{x}+4.3 ; \mathrm{p}<0.001$.

Correlation of heart function with atrial natriuretic peptide and cGMP plasma concentrations

To investigate the correlation between heart function (left ventricular ejection fraction and right ventricular ejection fraction) and atrial natriuretic peptide or cGMP plasma concentrations, 10 healthy individuals
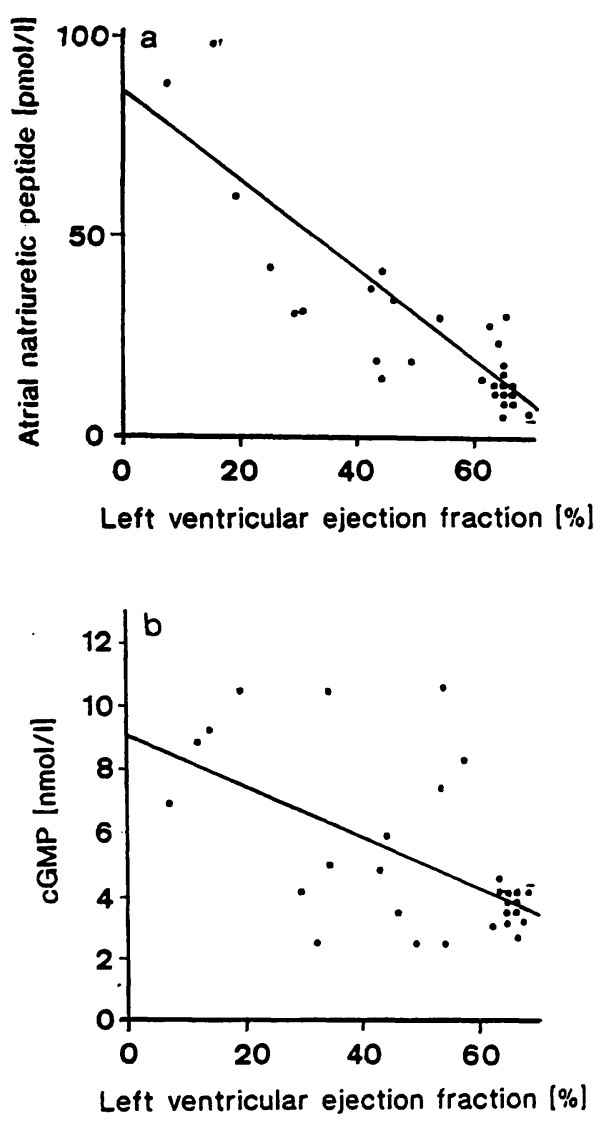

Fig. 2. Correlation between atrial natriuretic peptide (a) and cGMP (b) concentrations in plasma and left ventricular ejection fraction.

(a) correlation between atrial natriuretic peptide and left ventricular ejection fraction:

$\mathrm{n}=29 ; \mathrm{r}=-0.76 ; \mathrm{y}=-3.3 \mathrm{x}+254 ; \mathrm{p}<0.001$.

(b) correlation between cGMP and left ventricular ejection fraction:

$\mathrm{n}=29 ; \mathrm{r}=-0.58 ; \mathrm{y}=-0.1 \mathrm{x}+9.1 ; \mathrm{p}<0.001$.

and 19 patients with chronic heart disease were examined. Left ventricular ejection fraction and atrial natriuretic peptide correlated with a correlation coefficient of $\mathrm{r}=-0.76(\mathrm{y}=3.30 \mathrm{x}+2.6 ; \mathrm{p}<0.001)$ (fig. 2a). The correlation between left ventricular ejection fraction and cGMP (fig. 2b) was $r=-0.58$; $(y=0.1 x+9.1 ; p<0.001)$. During rest right ventricular ejection fraction was within the normal range in all patients examined ( $>38 \%$ ); no correlation be-tween right ventricular ejection fraction and atrial natriuretic peptide $(r=0.04)$ or cGMP $(r=0.03)$ plasma concentrations could be established.

In patients who had undergone orthotopic heart transplantation, there appeared to be no correlation between heart function (left ventricular ejection fraction or right ventricular ejection fraction) and atrial natriuretic peptide or cGMP concentrations. Furthermore, under exercise conditions, neither atrial natriuretic peptide nor cGMP showed any correlation with scintigraphically measured left ventricular ejection fraction or right ventricular ejection fraction. 
Tab. 1. Plasma atrial natriuretic peptide and cGMP concentrations in patients with heart disorders and in healthy controls

\begin{tabular}{|c|c|c|c|c|c|c|}
\hline & \multicolumn{3}{|c|}{ During rest } & \multicolumn{3}{|c|}{ During exercise } \\
\hline & $\mathrm{N}$ & $\begin{array}{l}\text { Atrial natriuretic } \\
\text { peptide } \\
\bar{x} \pm S D \\
(\mathrm{pmol} / \mathrm{l})\end{array}$ & $\begin{array}{l}\text { cGMP } \\
\bar{x} \pm \mathrm{SD} \\
(\mathrm{nmol} / \mathrm{l})\end{array}$ & $N$ & $\begin{array}{l}\text { Atrial natriuretic } \\
\text { peptide } \\
\bar{x} \pm S D \\
(\mathrm{pmol} / \mathrm{l})\end{array}$ & $\begin{array}{l}\text { cGMP } \\
\bar{x} \pm S D \\
(\mathrm{nmol} / \mathrm{l})\end{array}$ \\
\hline $\begin{array}{l}\text { Controls } \\
\text { Heart disease } \\
\text { Orthotopic heart transplantation }\end{array}$ & $\begin{array}{l}14 \\
20 \\
16\end{array}$ & $\begin{array}{l}11.0 \pm 6.8 \\
37.0 \pm 25.5^{*} \\
58.7 \pm 18.8^{*}\end{array}$ & $\begin{array}{l}3.0 \pm 0.97 \\
5.6 \pm 3.3^{*} \\
8.7 \pm 1.9^{*}\end{array}$ & $\begin{array}{l}16 \\
12\end{array}$ & $\begin{array}{r}59.1 \pm 45.1^{*} \\
102.6 \pm 30.2^{*}\end{array}$ & $\begin{array}{c}7.54 \pm 3.0^{*} \\
11.6 \pm 2.1^{*}\end{array}$ \\
\hline
\end{tabular}

SD: standard deviation

* All patients exhibited, during rest as well as during exercise, significantly $(p<0.001)$ higher plasma concentrations than healthy controls. Plasma atrial natriuretic peptide and cGMP concentrations of transplanted patients were significantly $(p<0.01)$ increased in comparison with other patients.

Atrial natriuretic peptide and cGMP plasma concentrations in different patient groups

The plasma atrial natriuretic peptide and cGMP concentrations of 14 healthy individuals, 20 patients suffering from chronic heart disease and 16 after orthotopic heart transplantation are presented in table 1. All patients had significantly higher values of atrial natriuretic peptide and cGMP than healthy individuals $(p<0.01)$. Plasma concentrations of atrial natriuretic peptide and cGMP in transplanted patients were significantly higher than those of patients with chronic heart disease. This was valid during rest as well as exercise. It is noteworthy that orthotopic heart transplantation patients showed normal mean left and right ventricular ejection fractions during rest as well as during exercise (left ventricular ejection fraction rest: $57 \pm 8 \%$, left ventricular ejection fraction exercise $66 \pm 8 \%$; right ventricular ejection fraction rest: $53 \pm 5 \%$, right ventricular ejection fraction exercise $58 \pm 7 \%$ ). Only two individuals in this group did not show an exercise-induced increase of right ventricular ejection fraction.

However, in all cases a significant rise in both atrial natriuretic peptide and CGMP concentrations were observable during exercise.

\section{Discussion}

While a correlation between atrial natriuretic peptide and CGMP plasma concentrations has been shown in children as well as adult patients $(10,11)$ suffering from various heart diseases during rest, no such studies appear to have been reported in patients during exercise. The present study demonstrates that a relationship exists between atrial natriuretic peptide and cGMP concentrations during supine exercise in the chronic stable stage of cardiac disease.
We observed a good correlation between atrial natriuretic peptide and ventricular function, whereas the correlation between left ventricular ejection fraction and cGMP was significant but inferior to that of atrial natriuretic peptide and left ventricular ejection fraction (fig. 2b). This difference between left ventricular ejection fraction and cGMP in chronic cardiac disease may be caused by down regulation of atrial natriuretic peptide receptors resulting in a depressed release of $\operatorname{cGMP}(7,17)$. Direct response of the second messenger system to acute elevation of atrial natriuretic peptide during stress caused by bicycle exercise might be responsible for the better correlation $(r=0.81)$ of atrial natriuretic peptide and cGMP under exercise than under resting conditions ( $r=0.71$; fig. 1). These effects could be due to the regulation for atrial natriuretic peptide receptors. Changing or chronically elevated atrial natriuretic peptide concentrations might cause down regulation of the atrial natriuretic peptide receptor number, expression or sensitivty. This would lead to inhibition of the signal transduction with decreased cGMP release into the plasma.

An increase in both plasma atrial natriuretic peptide and cGMP has been reported in patients suffering from various heart diseases. Hirata et al. showed a good correlation between plasma concentrations of atrial natriuretic peptide and cGMP versus invasively measured haemodynamic variables during resting conditions $(10,11)$. Our data on the scintigraphic evaluation of heart function appear to be in accord with these findings (18). However, in patients after heart transplantation, this relationship between left ventricular ejection fraction and cGMP wàs absent. Despite normal right ventricular and left ventricular ejection fraction during rest and exercise, atrial natriuretic peptide and cGMP plasma concentrations were significantly higher than in patients suffering from other chronic heart diseases. It is possible that 
the observed elevation may be due, at least in part, to changes in fluid and electrolyte balance caused by corticoid intake, as well as the influence of other immunosuppressive drugs (19). Since angiographic controls one year after heart transplantations revealed elevated left ventricular filling pressures in these patients (data not shown), another factor involved in elevated atrial natriuretic peptide or cGMP plasma concentrations in patients after heart transplantation might be impaired ventricular filling, despite normal systolic ventricular function $(20-22)$.

No significant correlation was seen between impaired ventricular function and cGMP or atrial natriuretic peptide plasma concentrations during exercise. Neither could we establish any relationship between increased ejection fractions and increase of atrial natriuretic peptide or cGMP concentrations during the change from rest to exercise.

However, the present study demonstrates that in all patients with or without scintigraphically assessed

\section{References}

1. De Bold, A. J., Borenstein, H. B., Veress, A. T. \& Sonnenberg, $H$. (1981) A rapid and potent natriuretic response to intravenous injection of atrial myocardial extract in rats. Life Sci. 28, 89-94.

2. Yamaji, T., Ishibashi, M., Nakaoka, M., Imataka, K., Amano, M. \& Fujii, J. (1985) A possible role of ANF in polyuria associated with paroxysmal atrial arrhythmias. Lancet $i, 1211$.

3. Burnett, J. C., Kao, P. C., Hu, D. C., Heser, D. W., Heublein, D., Granger, J. P., Opgenorth, T. G. \& Raader, G. S. (1986) Atrial natriuretic peptide elevation in congestive heart failure in human. Science $231,1145-1147$.

4. Rascher, W., Tulalssay, T. \& Lang, R. E. (1985) ANP in plasma of volume-overloaded children with chronic renal failure. Lancet $i, 303-305$.

5. Burnett Jr., J. C. (1987) Atrial natriuretic factor secretion: physiological regulation and implication in cardiac vascular disease (Review). Curr. Opin. Cardiol. 2, 653-659.

6. Stasch, J. P., Hirth, C., Kazda, S. \& Wohlfeil, S. (1986) The elevation of cyclic GMP as a response to acute hypervolemia is blocked by a monoclonal antibody directed against atrial natriuretic paptide. Eur. J. Pharmacol. 129, $165-168$.

7. Hirata, Y., Tomita, M., Takada, S. \& Yoshimi, H. (1985) Vascular receptor binding and cyclic GMP response by synthetic human and rat natriuretic peptides (ANP) and receptor down-regulation by ANP. Biochem. Biophys. Res. Commun. 128, 538-546.

8. Vorderwinkler, K. P., Artner-Dworzak, E., Jakob, G., Mair, J., Dienstl, F., Pichler, M. \& Puschendorf, B. (1991) Release of cyclic guanosine monophosphate evaluated as a diagnostic tool in cardiac disease. Clin. Chem. 37, 186-190.

9. Wencker, M., Hauptlorenz, S., Moll, W. \& Puschendorf, B. (1989) Influence of blood pressure, heart rate, age, and sex on concentrations of atrial natriuretic factor and cyclic GMP in 124 volunteers. Clin. Chem. 35, 1519-1523. impairment of systolic ventricular function (i.e. left ventricular and right ventricular ejection fraction during rest or exercise), plasma concentrations of cGMP as well as those of atrial natriuretic peptide correlated reasonably well, even at peak exercise.

Our data support the notion that cGMP, like atrial natriuretic peptide, is a suitable quantity for the biochemical evaluation of cardiac patients during exercise conditions. Since it is not compromised by preanalytical difficulties (8), it might be a better quantity for routine evaluations. However, changes in cGMP plasma concentrations alone do not reflect systolic ventricular function (as shown in patients after heart transplantation) and thus should not be interpreted without additional clinical information. Nevertheless, as unexplained cardiac symptoms are often the cause of extensive and time-consuming diagnostic efforts, assaying plasma cGMP concentrations might prove to be useful screening tool for diagnosing heart diseases.
10. Weil, J., Gerzer, R., Strom, T., Lang, R., Döhlemann, C., Knorr, D. \& Bidlingmaier, F. (1987) Increased plasma cyclic guanosine monophosphate concentrations in children with high levels of circulating atrial natriuretic peptide. Pediatrics $80,545-548$.

11. Hirata, Y., Ishii, M., Matsuoka, H., Sugimoto, T., lizuka, M., Chida, Y., Serizawa, T. \& Matsuo, H. (1987) Plasma concentrations of $\alpha$-human atrial natriuretic polypeptide and cyclic GMP in patients with heart disease. Am. Heart J. 113, 1463-1469.

12. Weil, J., Lang, R. E., Suttmann, H., Rampf, U., Bidlingmaier, F. \& Gerzer, F. (1985) Concomittant increase in plasma ANP and cyclic GMP during volume loading. Klin. Wochenschr. 63, 1265-1268.

13. Gerzer, R., Witzgall, H., Tremblac, J., Gutkowska, J. \& Hamet, P. (1985) Rapid increase in plasma and urinary cGMP after bolus injection of ANF in man. J. Clin. Endocrinol. Metab. 61, 1217-1219.

14. Fridrich, L., Szekeres, T., Hartter, E., Schweighofer, F., Gassner, A. \& Laczkovic, A. (1989) Correlation betweenheart disorders and concentrations of directly measured atrial natriuretic peptide in plasma. Clin. Chem. 35, 435439.

15. Fridrich, L., Gassner, A. \& Sommer, G. (1988) Prognostic value of supine scintigraphic heart function and simultaneous conventional exercise response in patients after myocardial infarction. Clin. Cardiol. 11, 215-220.

16. Fridrich, L., Weihs, W. \& Sommer, G. (1988) Radionuclide detection of mild valvular regurgitation: its significance as assessed by Doppler sonography. Eur. J. Nucl. Med. 14, $125-130$.

17. Hauptlorenz, S., Puschendorf, B., Wencker, M. \& Dienstl, $F$. (1989) Influence of $\beta$-Blockade on Ejection Fraction, ANP, and cGMP in Patients After Myocardial Infarction. J. Am. Med. Ass. 262, 2996-2997. 
18. Waldhäusl, W., Vierhapper, H. \& Nowotny, P. (1986) Prolonged administration of human ANF in healthy men: Evanescent effects on diuresis and natriuresis. J. Clin. Endocrinol. Metab. 62, 956-959.

19. Saxenhofer, H., Angst, M. \& Weidmann, P. (1988) Corticosteroid induced stimulation of atrial natriuretic peptide in man. Acta Endocrinol. (Copenhagen) 118, 179-186.

20. Singer, D. R. J., Buckley, M. G., MacGregor, G. A., Khaghani, A., Banner, N. R. \& Yacoub, M. H. (1986) Raised concentration of atrial natriuretic peptides in cardiac transplant recipients. Br. Med. J. 293, 1391-1397.
21. Bonow, R. O., Vitale, D. F., Bacharach, L., Maron, B. J. \& Green, M. V. (1988) Effects of aging on asynchronous left ventricular regional human subjects. J. Am. Coll. Cardiol. $11,50-58$.

22. Sax, F. L., Rush, J. E. \& Cannon', R. O. (1988) Impaired left ventricular diastolic filling in symptomatic compared to asymptomatic hypertensive patients (Abstract). J. Am. Coll. Cardiol. 11, 81.

Univ. Doz. Dr. Leo Fridrich

Klinik für Nuklearmedizin

der Universität Innsbruck

Anichstraße 35

A-6020 Innsbruck

Austria 